\title{
Safety and efficacy of ferric carboxy maltose in pregnant women- a pilot study
}

\author{
Vijaya Harsoor $^{1}$, Shaila Chikkagowdra ${ }^{1 *}$, Aniruddha R. H. ${ }^{2}$, Vanaja D. ${ }^{1}$
}

\author{
${ }^{1}$ Department of Obstetrics and Gynecology, VIMS, Ballari, Karnataka, India \\ ${ }^{2}$ Department of Obstetrics and Gynecology, AIMS and RC, Devanahalli, Bengaluru, Karnataka, India
}

Received: 11 December 2020

Accepted: 13 January 2021

\author{
*Correspondence: \\ Dr. Shaila Chikkagowdra, \\ E-mail: shailagbgoud@gmail.com
}

Copyright: ( $)$ the author(s), publisher and licensee Medip Academy. This is an open-access article distributed under the terms of the Creative Commons Attribution Non-Commercial License, which permits unrestricted non-commercial use, distribution, and reproduction in any medium, provided the original work is properly cited.

\begin{abstract}
Background: Iron deficiency is a common nutritional deficiency amongst women of childbearing age. It is associated with significant maternal, fetal and infant morbidity. Current options for treatment include oral iron, parenteral iron and red blood cell transfusions. Ferric carboxy maltose is a newer i.v. iron formulation which can be used at high doses with rapid administration. This study was undertaken to assess the safety and efficacy in pregnant women.

Methods: Prospective observational study was conducted in VIMS Ballari. 50 pregnant women between 28-36 weeks of gestation having moderate anemia with confirmed iron deficiency were administered with $1000 \mathrm{mg}$ of ferric carboxy maltose (FCM). These women were followed after 2 weeks, 4 weeks and till delivery. Safety and efficacy were assessed.

Results: There was significant improvement in both hemoglobin and serum ferritin levels $(\mathrm{p}<0.01)$. None of them had significant reactions.

Conclusions: Ferric carboxy maltose is well tolerated. Ability to transfuse in single high dose makes it a preferred drug for faster and higher replenishment of iron stores and correction of hemoglobin levels during pregnancy especially in third trimester.
\end{abstract}

Keywords: Iron deficiency, Ferric carboxy maltose, Parenteral iron therapy, Peripartum anemia

\section{INTRODUCTION}

Iron deficiency is a common nutritional deficiency amongst women of childbearing age. Peri-partum iron deficiency anemia (IDA)is associated with significant maternal, fetal and infant morbidity causing major public health problem in India. ${ }^{1,2}$ It contributes in preterm birth, fetal growth restriction, intrauterine fetal death, low Apgar scores and infection in fetus and infants. ${ }^{3-5}$ Peripartum maternal iron deficiency has also been associated with childhood developmental problems and negative mother-infant interactions such as an increase in negative statements and decreased responsiveness. ${ }^{6,7}$ Progression from iron deficiency to iron deficiency anaemia (IDA) in pregnancy is common due to the increased demand for iron to support maternal haemoglobin mass expansion and for the growing fetus and placenta. ${ }^{8}$ This is further aggravated by blood loss associated with delivery. Deliveries by both caesarean section and vaginal deliveries that require instrumentation/intervention represent an even greater risk increasing a woman's vulnerability for peri-partum blood transfusion, chronic iron deficiency anaemia and iron store depletion, all compromising maternal well-being. ${ }^{9,10}$ However, this recognition has not resulted in a universal approach of iron supplementation. ${ }^{11}$

For many decades the mainstay treatment of IDA has been oral iron and red blood cell (RBC) transfusions. However, oral iron supplementation can lead to significant side effects resulting in non-compliance in many patients and the risks for RBC transfusion are well described and should be avoided whenever possible. ${ }^{12}$ Intravenous iron formulations offer an alternative 
approach in the presence of moderate or severe anaemia, intolerance of or non-adherence to oral iron and malabsorption states. ${ }^{13}$ Ferric carboxymaltose (FCM) is an i.v. iron formulation which can be used at high doses and allows rapid administration (up to $1000 \mathrm{mg}$ in a single dose infused in 15 minutes). Because it is free of dextran and its derivatives, FCM does not cross-react with dextran antibodies and never needed the administration of a test dose. ${ }^{2,3}$ The FCM molecules consist of an iron-hydroxide core chelated in a carbohydrate shell and this complex is taken up as a whole by macrophages, leading to very low levels of nontransferrin bound iron, avoiding iron toxicity and oxidative stress. ${ }^{3}$ FCM's clinical efficacy and safety have been proven in several large clinical studies across different indications with up to one-year follow-up in severe disease types such as chronic kidney disease and chronic heart failure. ${ }^{14-24}$ At least four postpartum studies compared the safety and efficacy of FCM versus oral iron. $^{22-25}$ Faster and greater Hb-responses were achieved in FCM-treated patients compared to those receiving oral iron and FCM replenished iron stores efficiently. Few studies or cases with limited numbers of FCM-treated pregnant women have been reported. ${ }^{26-29}$

This study was undertaken to evaluate safety and efficacy of FCM during pregnancy.

\section{METHODS}

This prospective observational study was conducted in VIMS, Ballari. Pregnant women in third trimester between 28 weeks to 36 weeks of gestation attending antenatal clinic with moderate anemia ( $\mathrm{Hb} 8$ to $10 \mathrm{gm} / \mathrm{dl}$ ) were included in the study. After taking the consent complete blood counts with peripheral smear and iron studies of all patients were done and iron deficiency was confirmed. Women who were pretreated with other i.v. preparations, blood transfusion, megaloblastic, dimorphic anemia or other type of anemia were excluded after investigation. Total 50 cases were enrolled in the study.

Cases were transfused with Inj. FCM 1000mg in 100ml NS IV over 15-20 minutes. Pre and post transfusion vitals were monitored and women were watched for any reactions during the procedure.

These women were fallowed and reassessed with investigations and sense of wellbeing at the end of 2 weeks and 4 weeks after the transfusion. They were fallowed till delivery and investigations repeated 24 hours after the delivery. Maternal and fetal complications noted.

\section{Statistical analysis}

The collected data was compiled in EXCEL sheet and Master sheet was prepared. For analysis of this data SPSS (Statistical Software for social Sciences) software version $24^{\text {th }}$ was used. Qualitative was represented in form values and percentages. One sided ANOVA test was applied to check association between different parameters. $\mathrm{P}$ value was checked at $5 \%$ level of significance.

\section{RESULTS}

Among 50 patients, 2 had transfusion reactions which were managed conservatively and transfusion was stopped. They were advised oral haematinics and examined postnatally with CBC, PS and Iron profile. Their $\mathrm{Hb}$ levels and serum ferritin levels did not show much increase postnatally.

Table 1: Socio-demographic profile of the study subjects $(\mathbf{n}=\mathbf{5 0})$.

\begin{tabular}{|lll|}
\hline Variable & Frequency & Percent \\
\hline Age group & & \\
\hline 18-20 years & 12 & 24 \\
\hline 21-25 years & 23 & 46 \\
\hline 26-30 years & 15 & 30 \\
\hline Mean \pm SD & $23.32 \pm 3.53$ & \\
\hline Socio-economic status & & \\
\hline Lower & 17 & 34 \\
\hline Lower middle & 18 & 36 \\
\hline Middle & 12 & 24 \\
\hline Upper middle & 3 & 6 \\
\hline
\end{tabular}

Table 2: Associated risk factors among the study subjects $(\mathbf{n}=\mathbf{5 0})$.

\begin{tabular}{|lll|}
\hline Risk factors & Frequency & Percent \\
\hline Hypothyroidism & 1 & 2 \\
\hline Previous 1 ectopic & 1 & 2 \\
\hline Previous 1 LSCS and 2 VBAC & 1 & 2 \\
\hline Previous 2 LSCS & 1 & 2 \\
\hline Previous LSCS & 11 & 22 \\
\hline Rh negative status & 2 & 4 \\
\hline Nil & 33 & 66 \\
\hline Total & 50 & 100 \\
\hline
\end{tabular}

CBC and Iron profile were repeated at 2 weeks and 4 weeks post transfusion for all patients. 11 patients had first fallow up at 2 weeks post transfusion, which showed modest elevation in $\mathrm{Hb}$ and serum ferritin. But they delivered before second fallow up at 4 weeks. Postnatal investigations showed modest elevation which was statistically significant.

2 patients delivered within 2 weeks of transfusion hence first fallow up was done post-natal period and there was statistically significant elevation in the markers.

For the other 35 patients, $\mathrm{CBC}$ and Iron profile were repeated at 2 weeks and 4 weeks post transfusion and also post-partum and these were compared. Majority 23 (46\%) were in the age group of 21-25 years. $44 \%$ were primigravidae. Most of them 18 (36\%) belonged to lower 
middle class followed by lower class, $17(34 \%) .33$ $(66 \%)$ did not have any associated risk factors, $34(68 \%)$ had not taken tablets regularly. $31(62 \%)$ were clinically pale.

Table 3: Obstetric profile of the study subjects $(n=50)$.

\begin{tabular}{|lll|}
\hline Parameter & Frequency & Percent \\
\hline Gravida & 22 & 44 \\
\hline Gravida 1 & 17 & 34 \\
\hline Gravida 2 & 5 & 10 \\
\hline Gravida 3 & 1 & 2 \\
\hline Gravida 4 & 5 & 10 \\
\hline Gravida 5 & & \\
\hline Parity & 6 & 12 \\
\hline Para 0 & 13 & 26 \\
\hline Para 1 & 7 & 14 \\
\hline Para 2 & 1 & 2 \\
\hline Para 3 & 1 & 2 \\
\hline Para 4 & 22 & 44 \\
\hline NA & & \\
\hline Living & 6 & 12 \\
\hline Living 0 & 13 & 26 \\
\hline Living 1 & 8 & 16 \\
\hline Living 2 & 1 & 2 \\
\hline Living 3 & 22 & 44 \\
\hline NA & & \\
\hline Abortion & 16 & 32 \\
\hline Abortion 0 & 8 & 16 \\
\hline Abortion 1 & 4 & 8 \\
\hline Abortion 2 & 22 & 44 \\
\hline NA & & \\
\hline
\end{tabular}

Table 4: Compliance with prophylactic IFA tablets $(n=50)$.

\begin{tabular}{|lll|}
\hline Treatment regularity & Frequency & Percent \\
\hline Regularly taken & 34 & 68 \\
\hline Irregularly taken & 14 & 28 \\
\hline Not taken & 02 & 4 \\
\hline
\end{tabular}

Table 5: Clinical appearance of the patient.

\begin{tabular}{|lll|}
\hline Pallor & Frequency & Percent \\
\hline Present & 31 & 62 \\
\hline Absent & 19 & 38 \\
\hline
\end{tabular}

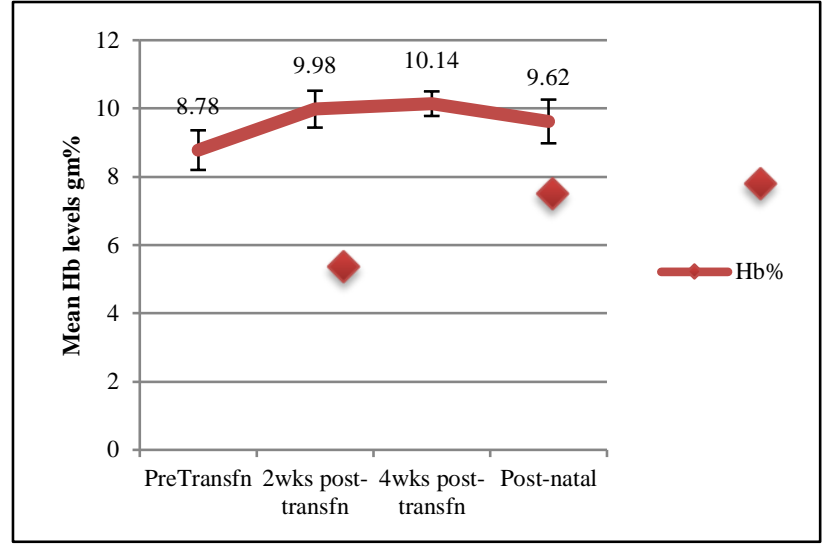

Figure 1: Comparison of $\mathrm{Hb}$ levels at different intervals of time.

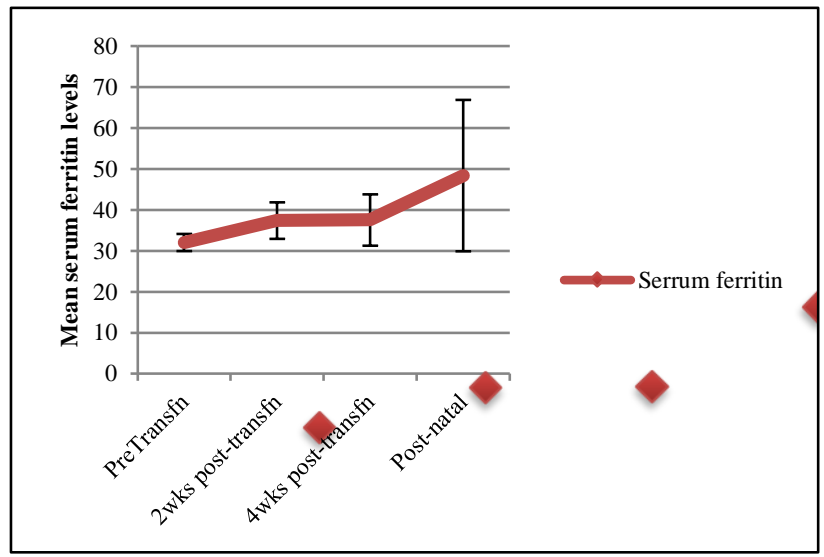

Figure 2: Comparison of serum ferritin levels at different intervals of time.

Table 6: Comparison of hematological parameters at different intervals of time before and after transfusion of ferric carboxy maltose.

\begin{tabular}{|lllllllllll|} 
Variable & $\begin{array}{l}\text { Pre-transfusion } \\
(\mathbf{n = 5 0})\end{array}$ & \multicolumn{2}{l}{$\begin{array}{l}\text { 2 weeks post- } \\
\text { transfusion }(\mathbf{n}=\mathbf{4 6})\end{array}$} & $\begin{array}{l}\text { 4 weeks post- } \\
\text { transfusion }(\mathbf{n}=\mathbf{3 5})\end{array}$ & $\begin{array}{l}\text { Postnatal } \\
(\mathbf{n = 4 7})\end{array}$ \\
\hline Mean & SD & Mean & SD & Mean & SD & Mean & SD & $<0.001$ \\
\hline RBC & 8.78 & 0.58 & 9.98 & 0.54 & 10.14 & 0.36 & 9.62 & 0.64 & $<0.001$ \\
\hline MCV & 3.50 & 0.51 & 3.26 & 0.65 & 4.03 & 0.57 & 3.91 & 0.83 & $<0.001$ \\
\hline MCH & 23.72 & 1.91 & 74.80 & 7.31 & 75.20 & 4.12 & 74.36 & 4.22 & $<0.001$ \\
\hline MCHC & 22.18 & 1.65 & 23.96 & 2.11 & 24.43 & 1.80 & 23.17 & 2.23 & 0.036 \\
\hline PI & 2.90 & 0.74 & 24.37 & 2.48 & 24.71 & 1.30 & 24.21 & 1.82 & $<0.001$ \\
\hline SI & 85.72 & 2.51 & 91.87 & 3.92 & 90.34 & 6.86 & 92.83 & 19.15 & 0.006 \\
\hline SF & 32.02 & 2.09 & 37.39 & 4.46 & 37.51 & 6.27 & 48.36 & 18.49 & $<0.001$ \\
\hline TIBC & 560.00 & 104.59 & 492.83 & 86.50 & 507.14 & 67.33 & 520.85 & 51.32 & 0.001 \\
\hline TS & 14.74 & 2.15 & 17.22 & 1.32 & 17.74 & 1.54 & 17.74 & 2.22 & $<0.001$ \\
\hline
\end{tabular}

*One sided ANOVA test is applied 
Table 6 shows the means and standard deviations of various parameters of $\mathrm{CBC}$ and iron profile. One sided ANOVA test was applied and was found that there is statistically significant difference between pre transfusion, post transfusion and post-natal values among the following parameters- $\mathrm{Hb}$, RBC Count, MCV, MCHC, platelet count, and serum ferritin levels at different intervals of time.

\section{DISCUSSION}

Maximum number of patients (46\%) were 21-25 years, $44 \%$ were primigravids, $70 \%(36 \%+34 \%)$ belonging to lower middle and lower socio-economic status indicating that nutritional anaemia exists in this population even before the first conception. Many (66\%) did not have any associated risk factors implying multifactorial health issue. $68 \%$ of our women had not taken IFA tablets regularly in spite of ANC visits as a part of so many national programmes due to lack of compliance. Interestingly anaemia was noted in $28 \%$ of women who had taken regular oral iron preparations. Metallic taste, vomiting, diarrhoea and wrong method of consumption could explain the erratic absorption. This also shows that pregnant women taking IFA prophylaxis are not immune to anaemia.

Majority of the patients $(62 \%)$ were clinically pale. Rest (38\%) did not seem pale on clinical examination. This shows that though most moderate degree anaemia cases are apparent on clinical examination, some may be missed. $4 \%$ patients had transfusion reactions which were managed conservatively and transfusion was stopped. They were advised oral haematinics. This shows that though FCM is safer than Iron dextran in terms of anaphylactic reactions, it can rarely cause reactions, which warrants a thorough history of previous such reactions in all patients receiving i.v. iron preparations. Their Hb levels and S. Ferritin levels did not show much increase postnatally. This shows that, oral haematinics in these patients did not help much in overcoming anaemia in these patients.

For $70 \%$ of patients, CBC and iron profile were repeated at 2 weeks and 4 weeks post transfusion and also postpartum and these were compared with pre transfusion $\mathrm{CBC}$ and iron profile. Women also felt sense of wellbeing at those visits compared to pretransfusion. It was found that there was statistically significant difference between pre transfusion, post transfusion and post-natal values among the following parameters- $\mathrm{Hb}, \mathrm{RBC}$ count, $\mathrm{MCV}$, MCHC, platelet count, serum ferritin and transferrin saturation. This shows that i.v. FCM is beneficial in improving the above parameters.

Comparison of mean $\mathrm{Hb}$ levels at different intervals of time was found to increase from pre transfusion values to post transfusion values. It was maximum at $4^{\text {th }}$ week post transfusion, and has a slight fall in the post-natal period, which is expected due to peripartum blood loss.
Nevertheless, these post-natal values are higher than the pre transfusion values. Comparison of mean serum ferritin levels at different intervals of time and was found to increase from pre transfusion values through post transfusion values, and was maximum at post-natal period, despite a fall in the $\mathrm{Hb}$ during post-natal period. This shows that, though the patient loses blood during peripartum period represented by the fall in the serum $\mathrm{Hb}$, the stores of iron stay intact represented by the consistent increase in serum ferritin even in post-natal period, in patients transfused with Injection FCM. In the first study on the use of FCM for treatment of IDA in pregnancy was published by Christoph et al concluded comparable safety and tolerability of FCM to iron sucrose and that FCM offers the advantage of a much higher iron dosage at a time reducing the need for repeated applications and increasing patient's comfort. The authors documented a comparable rise in $\mathrm{Hb}$ levels at the end of the study. ${ }^{26}$

Breymann et al compared FCM with oral iron therapy for treatment of iron deficiency anaemia in pregnancy. $\mathrm{Hb}$ levels improved at comparable rates in both groups. Patients in FCM group had significantly more women who achieved $\mathrm{Hb}>110 \mathrm{gm} / \mathrm{l}$ and within a shorter time frame and authors concluded to consider FCM to be firstline treatment option for correction of IDA especially in the third trimester of pregnancy. ${ }^{24}$ Froessler et al have documented significantly increased ferritin levels after FCM infusion in patients with anaemia and in women with iron deficiency and no anemia. ${ }^{28}$

In a recent systematic review to compare different injectable iron preparations in pregnancy, the authors failed to document the safety of any of the injectable iron therapies over others. The choice of injectable iron therapy is mainly determined by cost and convenience of administration. ${ }^{30}$

Though the cost of FCM drug is more compared to iron sucrose, when other parameters like multiple hospital visits and pricks, number of working days, travel are considered may not be much difference and in India. In fact, it can be provided free of cost under JSSK (Janani Shishu Suraksha Karyakram) scheme for pregnant women by the Indian Government. ${ }^{31}$

\section{CONCLUSION}

Single high dose administration of FCM even during third trimester resulted in rapid replenishment of iron stores in pregnancy as well as postpartum period. No relevant safety concerns regarding mother and foetus were identified and was well tolerated. Earlier administration in storage depletion stage may still increase the efficacy and prevent anaemia related complications during antenatal period and may contribute in safe motherhood initiative. However further larger studies can be contemplated for safety and efficacy. 


\section{ACKNOWLEDGMENTS}

Author would like to thank Dr. Suyajna D. Joshi who first introduced use of FCM in pregnancy in our place and was constant source of encouragement for its use. Dr. Raghavendra Bellara, Associate Professor, Department of $\mathrm{P}$ and SM, VIMS, Ballari, for guidance in statistical analysis. All the women who consented to participate in the study.

\section{Funding: No funding sources}

Conflict of interest: None declared

Ethical approval: The study was approved by the Institutional Ethics Committee

\section{REFERENCES}

1. Mishra V, Gandhi K, Roy P, Hokabaj S, Shah KN. Role of intravenous ferric carboxy-maltose in pregnant women with iron deficiency anaemia. J Nepal Health Res Counc. 2017;15(2):96-99.

2. Neiser S, Wilhelm M, Schwarz K, Funk F, Geisser P, Burckhardt S. Assessment of dextran antigenicity of intravenous iron products by an immunodiffusion assay. Portuguese J Nephrol Hypertens. 2011;25(3):219-24.

3. Geisser P. The pharmacology and safety profile of ferric carboxymaltose (Ferinject): structure/reactivity relationships of iron preparations. Portuguese $\mathbf{J}$ Nephrol Hypertens. 2009;23(1):11-6.

4. Rai RK, Fawzi WW, Barik A, Chowdhury A. The burden of iron-deficiency anaemia among women in India: how have iron and folic acid interventions fared? WHO South-East Asia J Public Health. 2018;7(1):18-23.

5. Lone FW, Qureshi RN, Emmanuel F. Maternal anaemia and its impact on perinatal outcome in a tertiary care hospital in Pakistan. East Mediterr Health J. 2004;10(6):801-7.

6. Beard J. Recent evidence from human and animal studies regarding iron status and infant development. J Nutr. 2007;137(2):524S-30S.

7. Perez EM, Hendricks MK, Beard JL, Murray-Kolb LE, Berg A, Tomlinson M, et al. Mother-infant interactions and infant development are altered by maternal iron deficiency anemia. J Nutr. 2005;135(4):850-5.

8. Gautam CS, Saha L, Sekhri K, Saha PK. Iron deficiency in pregnancy and the rationality of iron supplements prescribed during pregnancy. Medscape J Med. 2008;10(12):283.

9. Bodnar LM, Cogswell ME, McDonald T. Have we forgotten the significance of postpartum iron deficiency? Am J Obstet Gynecol. 2005;193(1):3644.

10. Ehrenthal DB, Chichester ML, Cole OS, Jiang X. Maternal risk factors for peripartum transfusion. J Womens Health. 2012;21(7):792-7.

11. Milman N. Postpartum anemia II: prevention and treatment. Ann Hematol. 2012;91(2):143-54.
12. Khalafallah A, Dennis A, Bates J, Bates G, Robertson IK, Smith L, et al. A prospective randomized, controlled trial of intravenous versus oral iron for moderate iron deficiency anaemia of pregnancy. J Intern Med. 2010;268(3):286-95.

13. Froessler B, Cocchiaro C, Saadat-Gilani K, Hodyl N, Dekker G. Intravenous iron sucrose versus oral iron ferrous sulfate for antenatal and postpartum iron deficiency anemia: a randomized trial. J Matern Fet Neonat Med. 2013;26(7):654-9.

14. Kulnigg S, Stoinov S, Simanenkov V, Dudar LV, Karnafel W, Garcia LC, et al. A novel intravenous iron formulation for treatment of anemia in inflammatory bowel disease: the ferric carboxymaltose (FERINJECT®) randomized controlled trial. Am J Gastroenterol. 2008;103(5):1182-92.

15. Steinmetz T, Tschechne B, Harlin O. Clinical experience with ferric carboxymaltose in the treatment of cancer- and chemotherapy-associated anaemia. Ann Oncol. 2013;24(2):475-82.

16. Evstatiev R, Marteau P, Iqbal T. FERGIcor, a randomized controlled trial on ferric carboxymaltose for iron deficiency anemia in inflammatory bowel disease. Gastroenterology. 2011;141(3)e2:846-53.

17. Anker SD, Comin Colet J, Filippatos G, Willenheimer R, Dickstein K, Drexler H, et al. Ferric carboxymaltose in patients with heart failure and iron deficiency. N Engl J Med. 2009;361(25):2436-48.

18. Van Wyck DB, Mangione A, Morrison J, Hadley PE, Jehle JA, Goodnough LT. Blood Management: largedose intravenous ferric carboxymaltose injection for iron deficiency anemia in heavy uterine bleeding: a randomized, controlled trial. Transfusion. 2009;49(12):2719-28.

19. Qunibi WY, Martinez C, Smith M, Benjamin J, Mangione A, Roger SD. A randomized controlled trial comparing intravenous ferric carboxymaltose with oral iron for treatment of iron deficiency anaemia of non-dialysis-dependent chronic kidney disease patients. Nephrol Dialysis Transplant. 2011;26(5)1599-607.

20. Covic A, Mircescu G. The safety and efficacy of intravenous ferric carboxymaltose in anaemic patients undergoing haemodialysis: a multi-centre, open-label, clinical study. Nephrol Dialysis Transplant. 2010;25(8): 2722-30.

21. Bailie GR, Mason NA, Valaoras TG. Safety and tolerability of intravenous ferric carboxymaltose in patients with iron deficiency anemia. Hemodial Int. 2010;14(1):47-54.

22. Seid MH, Derman RJ, Baker JB, Banach W, Goldberg C, Rogers R. Ferric carboxymaltose injection in the treatment of postpartum iron deficiency anemia: a randomized controlled clinical trial. Am J Obstet Gynecol. 2008;199(4):435-e1.

23. Van Wyck DB, Martens MG, Seid MH, Baker JB, Mangione A. Intravenous ferric carboxymaltose compared with oral iron in the treatment of 
postpartum anemia: a randomized controlled trial. Obstet Gynecol. 2007;110(2 Part 1):267-78.

24. Breymann C, Gliga F, Bejenariu C, Strizhova N. Comparative efficacy and safety of intravenous ferric carboxymaltose in the treatment of postpartum iron deficiency anemia. Int $\mathbf{J}$ Gynecol Obstet. 2008;101(1):67-73

25. Pfenniger A, Schuller C, Christoph P, Surbek D. Safety and efficacy of high-dose intravenous iron carboxymaltose vs. iron sucrose for treatment of postpartum anemia. J Perinat Med. 2012;40(4):397402 .

26. Christoph $\mathrm{P}$, Schuller C, Studer H, Irion O, De Tejada BM, Surbek D. Intravenous iron treatment in pregnancy: comparison of high-dose ferric carboxymaltose vs. iron sucrose. J Perinat Med. 2012;40(5):469-74.

27. Myers B, Myers O, Moore J. Comparative efficacy and safety of intravenous ferric carboxymaltose (Ferinject) and iron (III) hydroxide dextran (Cosmofer) in pregnancy. Obstet Med. 2012;5(3):105-7.

28. Froessler B, Collingwood J, Hodyl NA, Dekker G. Intravenous ferric carboxymaltose for anaemia in pregnancy. BMC Pregnanc Childbirth. 2014;14(1):15.

29. Froessler B, Dekker G, McAuliffe G. To the rescue: the role of intravenous iron in the management of severe anaemia in the peri-partum setting. Blood Transfus. 2015;13(1):150-2.

30. Qassim A, Mol BW, Grivell RM, Grzeskowiak LE. Safety and efficacy of intravenous iron polymaltose, iron sucrose and ferric carboxymaltose in pregnancy: a systematic review. ANZ J Obstet Gynaecol. 2018;58(1):22-39.

31. Mahey R, Kriplani A, Mogili KD, Bhatla N, Kachhawa G, Saxena R. Randomized controlled trial comparing ferric carboxymaltose and iron sucrose for treatment of iron deficiency anemia due to abnormal uterine bleeding. Int J Gynaecol Obstet. 2016;133(1):43-8.

Cite this article as: Harsoor V, Chikkagowdra S, Aniruddha RH, Vanaja D. Safety and efficacy of ferric carboxy maltose in pregnant women- a pilot study. Int J Reprod Contracept Obstet Gynecol 2021;10:647-52. 